\title{
UCRL-JRNL-223879
}

LAW RENCE LIVERMORE N A TIO N A L LABORATORY

\section{Enhanced Energy Confinement and Performance in a Low-Recycling Tokamak}

R. Majeski, R. Doerner, T. Gray, R. Kaita, R. Maingi, D. Mansfield, J. Spaleta, V. Soukhanovski, J. Timberlake, L. Zakharov

August 22, 2006

Physical Review Letters 
This document was prepared as an account of work sponsored by an agency of the United States Government. Neither the United States Government nor the University of California nor any of their employees, makes any warranty, express or implied, or assumes any legal liability or responsibility for the accuracy, completeness, or usefulness of any information, apparatus, product, or process disclosed, or represents that its use would not infringe privately owned rights. Reference herein to any specific commercial product, process, or service by trade name, trademark, manufacturer, or otherwise, does not necessarily constitute or imply its endorsement, recommendation, or favoring by the United States Government or the University of California. The views and opinions of authors expressed herein do not necessarily state or reflect those of the United States Government or the University of California, and shall not be used for advertising or product endorsement purposes. 


\title{
Enhanced Energy Confinement and Performance in a Low-Recycling Tokamak
}

\author{
R. Majeski, R. Doerner,* T. Gray, R. Kaita, R. Maingi,** D. Mansfield, J. Spaleta, V. \\ Soukhanovski,*** J. Timberlake, L. Zakharov \\ Princeton Plasma Physics Laboratory, Princeton, NJ, USA \\ *University of California at San Diego, La Jolla, CA, USA \\ **Oak Ridge National Laboratory, Oak Ridge, TN, USA \\ ***Lawrence Livermore National Laboratory, Livermore, CA, USA
}

\begin{abstract}
Extensive lithium wall coatings and liquid lithium plasma-limiting surfaces reduce recycling, with dramatic improvements in ohmic plasma discharges in the Current Drive eXperiment Upgrade (CDX-U). Global energy confinement times increase by up to $6 \times$. These results exceed confinement scalings such as $\operatorname{ITER} 98 \mathrm{P}(\mathrm{y}, 1)$ by $2-3 \times$, and represent the largest increase in confinement ever observed for an ohmic tokamak plasma. Measurements of $\mathrm{D}_{\alpha}$ emission indicate that global recycling coefficients decrease to approximately 0.3, the lowest documented for a magnetically confined hydrogen plasma.
\end{abstract}

PACS numbers: 52.55.Fa, 52.40.Hf, 52.25.Fi 
Many experiments have indicated that plasma performance is enhanced as the global wall recycling coefficient $\mathrm{R}$ is reduced. ${ }^{\mathrm{iiiiii}}$ Techniques such as divertor pumping and lithium wall coatings have reduced $\mathrm{R}$ by $5-15 \%$. The resultant changes in plasma performance were dramatic. In the Tokamak Fusion Test Reactor (TFTR), ${ }^{\text {iv }}$ a factor of two increase in the confinement time was produced with extensive lithium wall coatings of the carbon wall, and a $15 \%$ reduction in recycling. ${ }^{\mathrm{v}}$. In the DIII-D device, divertor cryopumping resulted in a strong increase in the edge pedestal temperature with only a modest decrease in global recycling. ${ }^{\mathrm{vi}}$ However, the very low global recycling regime ( $50 \%$ or less) has not been explored. Significant changes in tokamak discharge characteristics are predicted in this regime. ${ }^{\text {vii }}$ A candidate wall material for the minimization of recycling is metallic lithium, especially liquid lithium.

Experiments on the T11-M device in Russia have previously utilized a compact liquid lithium rail limiter, in combination with partial solid lithium coatings on the stainless steel vessel wall. ${ }^{\text {vii }}$ Initial experiments in the Current Drive eXperiment - Upgrade (CDX-U) also utilized a liquid lithium rail limiter similar to the T11-M system. ${ }^{\text {ix }}$ Here we report on the results of experiments in the CDX-U with large area $\left(600-2000 \mathrm{~cm}^{2}\right)$ liquid lithium limiters, in combination with full-wall lithium coatings up to $1000 \AA$ thick, which are applied between discharges. The use of liquid lithium as a plasma limiting surface ensures that deuterium does not "load" the surface of the lithium during initial stages of plasma operation, since the high diffusivity of deuterium in liquid lithium $\left(>10^{4} \mathrm{~cm}^{2} / \mathrm{sec}\right.$ at the $300-400{ }^{\circ} \mathrm{C}$ operating temperature) ensures that the surface region of the lithium is not saturated. Similarly, background gases present in the vacuum vessel (e.g. water) are dissolved into the liquid lithium rather than form a surface layer. Loading of the solid lithium coatings cannot be avoided, but contamination of the surface is reduced by depositing the lithium coating rapidly ( $<3$ minutes), and minimizing the time between deposition and the plasma discharge ( $<1$ minute).

Tokamak discharges in CDX-U with lithium wall and limiter coatings, and the liquid lithium limiter, exhibit significantly enhanced performance compared to discharges with uncoated plasma facing surfaces. The plasma facing surfaces in CDX-U are titanium carbide, boron carbide, and stainless steel. Transport in CDX-U prior to lithium operations has been previously characterized, ${ }^{\mathrm{x}}$ with global confinement times of approximately $1 \mathrm{msec}$, from kinetic measurements. In contrast, lithium operation has produced global confinement times of 6 msec. Confinement is strongly correlated with the level of recycling in these discharges. For the confinement data presented here, $\mathrm{R}$ was in the $50-60 \%$ range. However, global recycling was 
reduced to approximately 30\% for discharges that employed the largest available area of liquid lithium $\left(2000 \mathrm{~cm}^{2}\right)$.

The CDX-U is a small low aspect ratio tokamak, with major radius $\mathrm{R}_{0}=34 \mathrm{~cm}$, minor radius $\mathrm{a}=22 \mathrm{~cm}$, plasma elongation $\kappa=1.6$, and a toroidal magnetic field of $2 \mathrm{kG}$. The device typically operates in deuterium, with plasma current $<80 \mathrm{kA}$ and pulse length $<25 \mathrm{msec}$. For the experiments described here, the line-averaged density measured by a $2 \mathrm{~mm}$ microwave interferometer was $0.5-1 \times 10^{13} \mathrm{~cm}^{-3}$. The lower plasma limiter in CDX-U is a shallow, electrically heated, circular stainless steel tray with a radius of $34 \mathrm{~cm}$, a width of $10 \mathrm{~cm}$, and a depth of $0.6 \mathrm{~cm}$. The lithium tray limiter ${ }^{\mathrm{xi}}$ and the system used for filling the tray with a total of $300 \mathrm{~g}$ ( 0.6 liters) of lithium ${ }^{\mathrm{xii}}$ have been extensively described elsewhere. The lithium in the tray was either heated indirectly from below by means of resistive disk heaters attached to the bottom of the tray, or directly heated by a $1.6 \mathrm{~kW}$ magnetically guided electron beam incident on the surface of the lithium. Lithium coatings were also produced by a resistively heated oven evaporator, which was mounted on the vacuum vessel wall at the outer midplane. The lithium systems installed on CDX-U are indicated in Figure 1.

The lowest global recycling rates were inferred with the tray limiter completely filled with liquid lithium (approximately 0.6 liter, or $0.3 \mathrm{~cm}$ deep, with a surface area of $2000 \mathrm{~cm}^{2}$ ), and heated to $350^{\circ} \mathrm{C}$. The melting point of lithium is $180.5^{\circ} \mathrm{C}$, and at $350^{\circ} \mathrm{C}$ the evaporation rate is sufficient to coat other plasma limiting surfaces and the vacuum vessel inner wall with lithium at a rate of approximately 3-10 $\AA$ /minute, with higher deposition rates occurring on the center stack (inboard) limiting surfaces. Deposition rates were monitored with a commercial quartz crystal microbalance (Inficon Model XTM/2) at a distance of $1 \mathrm{~m}$ from the tray surface. CDX-U discharges are primarily limited on the centerstack, and secondarily on the lithium tray limiter. Recycling was measured by monitoring the relative level of $\mathrm{D}_{\alpha}$ radiation emitted at the centerstack midplane, which is the primary plasma contact point. A comparison of $\mathrm{D}_{\alpha}$ emission levels for plasma discharges with no lithium in the tray, and for discharges with the tray filled with liquid lithium at $350{ }^{\circ} \mathrm{C}$, is shown in Figure 2. The edge plasma density and electron temperature were measured with a triple Langmuir probe located at the last closed flux surface (i.e. at the outer limiter radius, located at $\mathrm{a}=22 \mathrm{~cm}$ or $\mathrm{R}=56 \mathrm{~cm}$ ), which maps to the inner contact point at the centerstack. The edge plasma density for both sets of discharges was approximately the same, $1 \times 10^{12} \mathrm{~cm}^{-3}$, although the edge electron temperature was $30 \mathrm{eV}$ in the case with 
lithium, compared to $20 \mathrm{eV}$ without lithium. In the case of a bare tray, the discharge was initiated with a vessel prefill, and no other gas fueling was required during the discharge. The bare tray discharges are therefore assumed to have a recycling coefficient $\mathrm{R}$ of approximately 1 . For discharges using the liquid lithium filled tray, strong gas fueling was necessary during the discharge in order to maintain the plasma density between 0.5 and $1 \times 10^{13} \mathrm{~cm}^{-3}$. The recycling coefficient for plasmas limited by liquid lithium is estimated by comparing the $\mathrm{D}_{\alpha}$ radiation emitted in that case with the $\mathrm{D}_{\alpha}$ radiation emitted during high recycling operation, and correcting for the difference in electron temperature. ${ }^{\text {xiii,xiv, xv }}$ This yields a recycling coefficient of 0.3 for full-tray liquid lithium operation $\left(2000 \mathrm{~cm}^{2}\right)$, at the centerstack.

During operation of the electron beam heating system in combination with the resistive oven evaporator the net recycling coefficient on the centerstack plasma limiting surfaces was generally higher. In this case only half the lithium-filled tray was liquefied and heated to $400-$ $450{ }^{\circ} \mathrm{C}$ by the electron beam, which provided thick (up to $1000 \AA$ ) lithium coatings, covering $180^{\circ}$ of the centerstack plasma contacting surfaces, in the $5-7$ minute interval between plasma discharges. Lithium coatings were produced on the remaining $180^{\circ}$ of the centerstack surface by the resistive oven evaporator, but the small $(<10 \mathrm{~g})$ lithium inventory in the oven limited the deposition rate and duration. $\mathrm{D}_{\alpha}$ emission levels from centerstack limiting surfaces coated by the resistive oven evaporator are also indicated in Figure 2. The average $D_{\alpha}$ emission level indicates an approximate $20 \%$ reduction in recycling when corrected for electron temperature differences for the half of the centerstack coated by the resistive oven evaporator. Thus global recycling under these conditions is estimated at 0.5 - 0.6. Data on energy confinement were only available under these conditions.

The effective particle confinement time $\tau_{\mathrm{p}}{ }^{*} \equiv \tau_{\mathrm{p}} /(1-\mathrm{R})$, where $\tau_{\mathrm{p}}$ is the particle confinement time, is estimated by measuring the density decay rate when gas fueling is terminated. In CDX-U, when lithium limiters and wall coatings are not employed, the density decay rate is too long to allow an estimate of $\tau_{\mathrm{p}}{ }^{*}$. Discharges which were initiated within a few minutes of a lithium coating cycle exhibited very rapid density pumpout after cessation of gas fueling, with $\tau_{\mathrm{p}}{ }^{*}$ as low as $2-3$ msec. Operation with a full lithium tray limiter at a temperature above $300{ }^{\circ} \mathrm{C}$ produced similar values of $\tau_{\mathrm{p}}{ }^{*}$. Discharges operated with older, chemically inactive lithium wall coatings exhibited intermediate values of $\tau_{\mathrm{p}}{ }^{*}$. Values of $\tau_{\mathrm{p}}{ }^{*}$ obtained under 
various operating conditions are indicated in Figure 3. The deuterium pumping rate represented by the lowest values of $\tau_{\mathrm{p}}{ }^{*}$ shown in Figure 3 is in the range of $2-3 \times 10^{21}$ particles/second.

Plasma equilibrium reconstructions were performed with the Equilibrium and Stability Code $(E S C)^{x v i}$, which has been modified to include the effects of vessel eddy currents on the magnetic signals. The energy confinement time $\tau_{\mathrm{E}}$ is given by ${ }^{\mathrm{xvii}}$

$$
\tau_{E}=\frac{W_{\text {kinetic }}}{\left(-\frac{d \Psi_{\text {edge }}}{d t}-P_{\text {mag }}-P_{\text {kinetic }}\right)}
$$

where $\mathrm{W}_{\text {kinetic }}$ is the stored plasma kinetic energy, and $\psi_{\text {edge }}$ is the edge poloidal flux, which yields the surface voltage $\mathrm{V}_{\text {edge }}=\left(\mathrm{d} \psi_{\text {edge }} / \mathrm{dt}\right)$. Since the CDX-U ohmic transformer is driven by capacitor banks, the discharge is not stationary, and so $\mathrm{P}_{\mathrm{mag}}$, the time derivative of the stored magnetic energy, and $\mathrm{P}_{\text {kinetic, }}$, the time derivative of the stored kinetic energy must be included in Eq. (1). We evaluate $\tau_{\mathrm{E}}$ when $\mathrm{P}_{\mathrm{mag}}$ is calculated to be zero from the ESC reconstructions, which

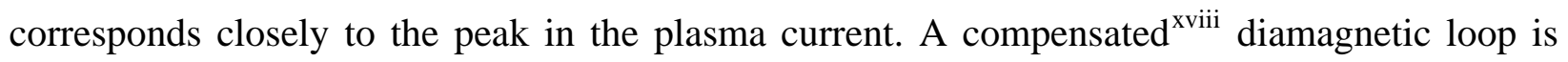
used in combination with magnetic reconstruction of the plasma boundary to measure the stored plasma kinetic energy. ESC also is used to determine the poloidal flux and hence the surface voltage near the time of peak plasma current. The plasma current is measured with a Rogowski coil internal to the vacuum vessel. A plot of the measured values of confinement time versus ITER98P $(y, 1)^{x i x}$ is shown in Figure 4. This scaling was the first to incorporate data from the START low aspect ratio tokamak, ${ }^{\mathrm{xx}}$ which was similar in size to CDX-U. Prior to the introduction of lithium PFCs to CDX-U, the measured confinement time fell in the range of 0.7 $1.1 \mathrm{msec},{ }^{10}$ Although this estimate was derived from measurements of the electron temperature and density rather than from magnetic reconstructions, it is in agreement with the passivated lithium results shown in Figure 4. However, the confinement time during active lithium operation exceeds previous results by up to a factor of six or more, and ITER98P(y,1) scaling by a factor of 2-3. Note that other than the incorporation of the lithium tray limiter and lithium wall coatings, and additional fueling capability (a second gas puffing system), no other changes in the CDX-U configuration were made in order to obtain this improvement in confinement. The plasma current and toroidal magnetic field, as well as the size of the plasma (determined by the limiter positions) were identical for the pre- and post-lithium discharges. The discharge electron density was similar, although in many cases the lithium discharges ran at somewhat lower 
density. The operating gas (deuterium) was the same in both cases. A transition back to lowered confinement could be reliably produced by allowing the lithium surfaces to passivate (collect background gases and acquire a high recycling coating) over days or weeks.

We emphasize that the plasma limiting surfaces for all discharges for which confinement time data are available were modified by lithium deposition, since the full set of magnetic diagnostics were only available after electron beam evaporation of the lithium in the limiter tray had been underway for several months. The high recycling regime could only be revisited by allowing the lithium coatings to passivate. However, even in the high recycling regime, oxygen and other impurities were greatly reduced compared to pre-lithium operation.

We find that confinement time is most strongly correlated with the density pumpout rate. We characterize the density pumpout rate by the time rate of change of the density $\mathrm{dn}_{\mathrm{e}} / \mathrm{dt}$ after fueling ceases, but before the plasma current begins to decrease and the equilibrium is modified. This characterization allows the inclusion of high recycling discharges, for which $\mathrm{dn}_{\mathrm{e}} / \mathrm{dt}$ is positive even after fueling is terminated, whereas $\tau_{\mathrm{p}}{ }^{*}$ is not meaningful under these circumstances. Figure 5 shows this correlation. High recycling discharges with constant or increasing density after cessation of fueling evidence modest confinement times. The production of discharges with enhanced confinement time is correlated with lowered recycling, as measured by the density pumpout rate. Note that, for all discharges plotted in Figures 4 and 5, gas fueling was terminated 1-2 msec before the peak in plasma current, when the measurement of confinement time occurred.

A factor of three increase in carbon IV impurity ion temperature, from $24 \mathrm{eV}$ to $71 \mathrm{eV}$, was also found for lithium limited discharges, as determined by Doppler broadening of the 466 nm C IV emission line. Carbon and oxygen emission were reduced by a factor of 10 in the lithium discharges. The loop voltage required to maintain a $70 \mathrm{kA}$ plasma current was reduced from $2-3 \mathrm{~V}$ in pre-lithium discharges to $0.5 \mathrm{~V}$ or less in lithium discharges.

In conclusion, the use of successively more aggressive levels of lithium wall coatings coupled with large-area liquid lithium limiting surfaces has a profound effect on energy confinement in a tokamak. Extensive coatings applied with a minimal time delay before discharge initiation produced a factor of six improvement in energy confinement time, the largest increase ever obtained in an ohmic tokamak. The observed increases in impurity ion and edge electron temperature suggest that low recycling lithium operation modifies the temperature profile. However, core electron temperature measurements were not available in CDX-U. Core 
electron measurements via Thomson scattering measurements are planned for the follow-on to CDX-U, the Lithium Tokamak eXperiment (LTX), which will begin operation in early 2007.

We thank Daren Stotler for assistance in the recycling estimates. Jon Menard, Michael Bell, Henry Kugel, and Mike Ulrickson also contributed valuable advice. This work supported by USDoE contract No. DE-AC02-76-CH0-3073 and contract W-7405-Eng-48 with UC, LLNL. 


\section{Reference}

${ }^{\mathrm{i}}$ J. D. Strachan, Nucl. Fusion 34, 1017 (1994).

ii JET or JT-60?

iii S. V. Mirnov et al., Fus. Eng. Des. 65, 455 (2003).

${ }^{i v}$ D. K. Mansfield et al., Nucl. Fusion 41, 1823 (2001).

${ }^{v}$ R. Budny, J. Nucl. Mater., 196-198, 462 (1992).

${ }^{v i}$ W. P. West, et al., Phys. Plasmas 9, 1970 (2002).

${ }^{v i i}$ L.E. Zakharov, et al., Fus. Eng. Des. 72, 149 (2004).

viii V. Evitkin, et al., Fus. Eng. Des. 56-57, 363 (2001).

${ }^{\mathrm{ix}} \mathrm{G}$. Antar et al., Fus. Eng. Des. 60, 157 (2002).

${ }^{\mathrm{x}} \mathrm{T}$. Munsat et al., Phys. Plasmas 9, 480 (2002).

${ }^{x i}$ R. Majeski, et al., J. Nucl. Mater. 313-316, 625 (2003).

${ }^{x i i}$ R. Majeski, et al., Fus. Eng. Des. 72, 121 (2004).

${ }_{\text {xiii }}$ L. C. Johnson and E. Hinnov, J. Quant. Spectrosc. Radiat. Transfer 13, 333 (1973).

${ }^{\text {xiv }}$ R. K. Janev, et al., J. Nucl. Mater. 121, 10 (1984)

${ }^{x v}$ DEGAS2 User's Manual, http://w3.pppl.gov/degas2

${ }^{x v i}$ L. E. Zakharov and A. Pletzer, Phys. Plasmas 6, 4693 (1999).

xvii I. H. Hutchinson, Principles of plasma diagnostics (Cambridge University Press, Cambridge, 2002), p. 22.

xviii L.E.Zakharov, V.D.Shafranov. in Reviews of Plasma Physics v.11, Ed. by Acad. M.A.Leontovich, Consultant Bureau, New York-London, p.153 (1986).

xix ITER Physics Basis Editors, Nucl. Fusion 39, 2137 (1999).

${ }^{\mathrm{xx}}$ O.J.W.F. Kardaun, in Proc. 18th IAEA Fusion Energy Conf., Sorrento, 2000 (IAEA,Vienna, 2001), CD-ROM file ITERP/04, unpublished. 


\section{Figure Captions}

Figure 1. Schematic of CDX-U, with the lithium and fueling systems, and the electron beam injector.

Figure 2. $\mathrm{D}_{\alpha}$ emission at peak plasma current for discharges without lithium wall coatings (diamonds), with modest levels of lithium wall deposition (6-10 $\AA / \mathrm{min}$, squares), and with extensive lithium wall coatings produced by evaporation from the lithium tray limiter (triangles).

Figure 3. Effective particle confinement time $\tau_{\mathrm{p}}{ }^{*}$ versus total number of deuterons injected for discharges with varying levels of lithium wall conditioning. The triangles denote results with the full lithium tray liquefied $\left(2000 \mathrm{~cm}^{2}\right)$, crosses denote electron beam evaporation and a $600 \mathrm{~cm}^{2}$ liquid lithium area, and squares denote operation with passivated lithium (no active evaporation or heating).

Figure 4. Measured energy confinement time versus ITER98P(y,1) confinement scaling. Discharges with passivated lithium walls are denoted by circles. Discharges with active lithium evaporation are denoted by squares.

Figure 5. Measured energy confinement time versus the density pumpout rate $\left(\mathrm{dn}_{\mathrm{e}} / \mathrm{dt}\right)$. The density pumpout rate is a good measure of the degree to which recycling is suppressed. 


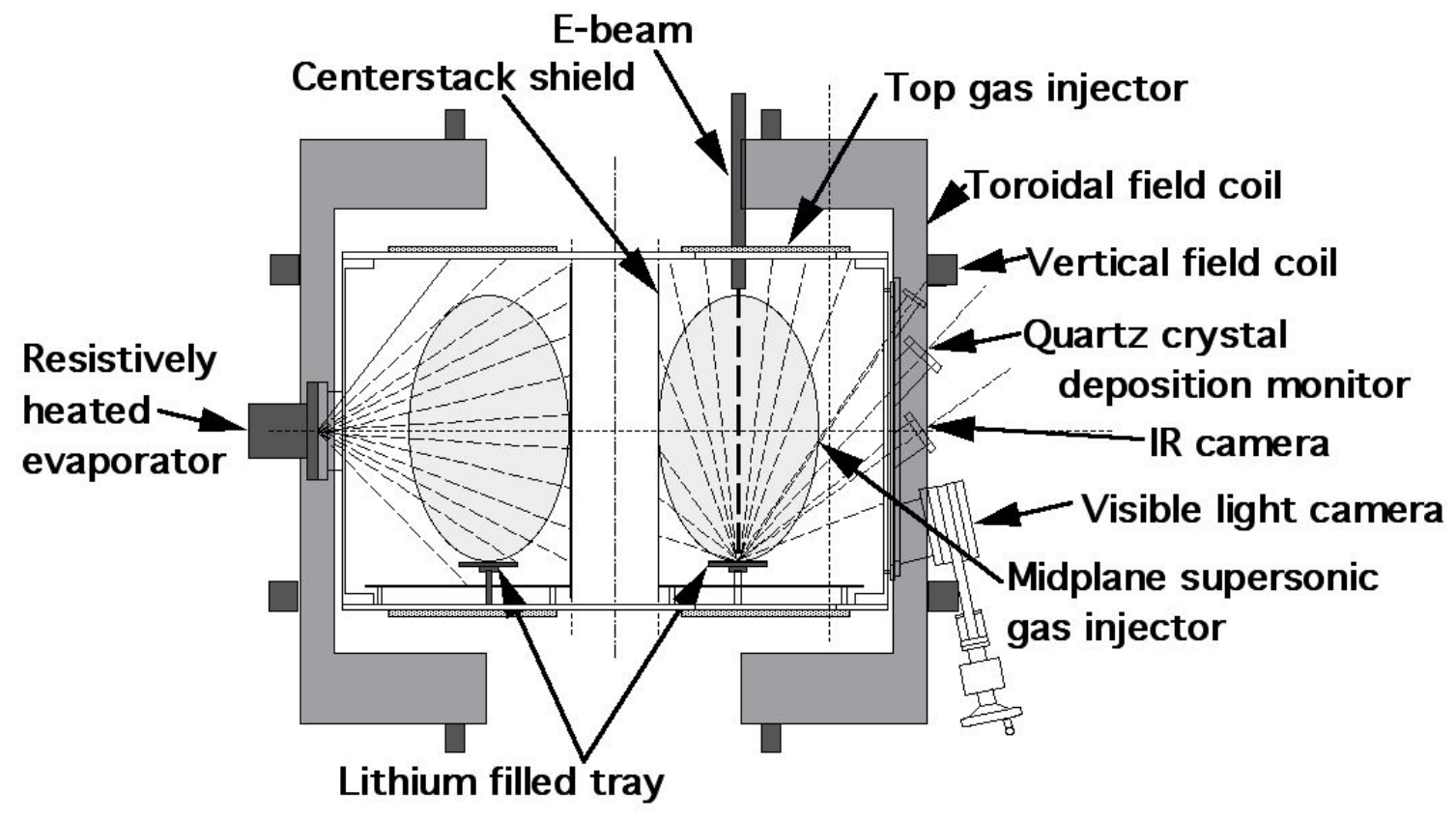

Figure 1 


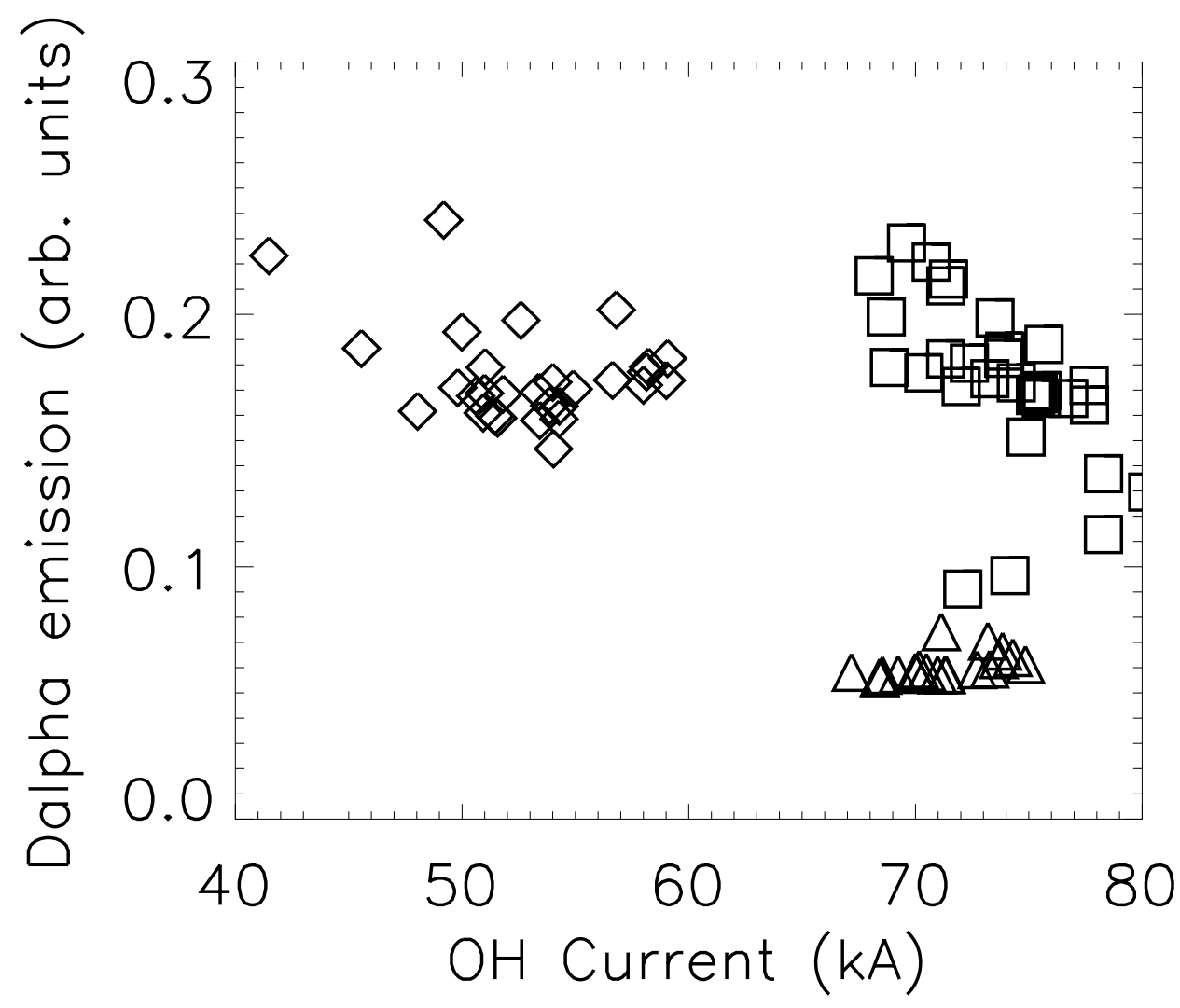

Figure 2 


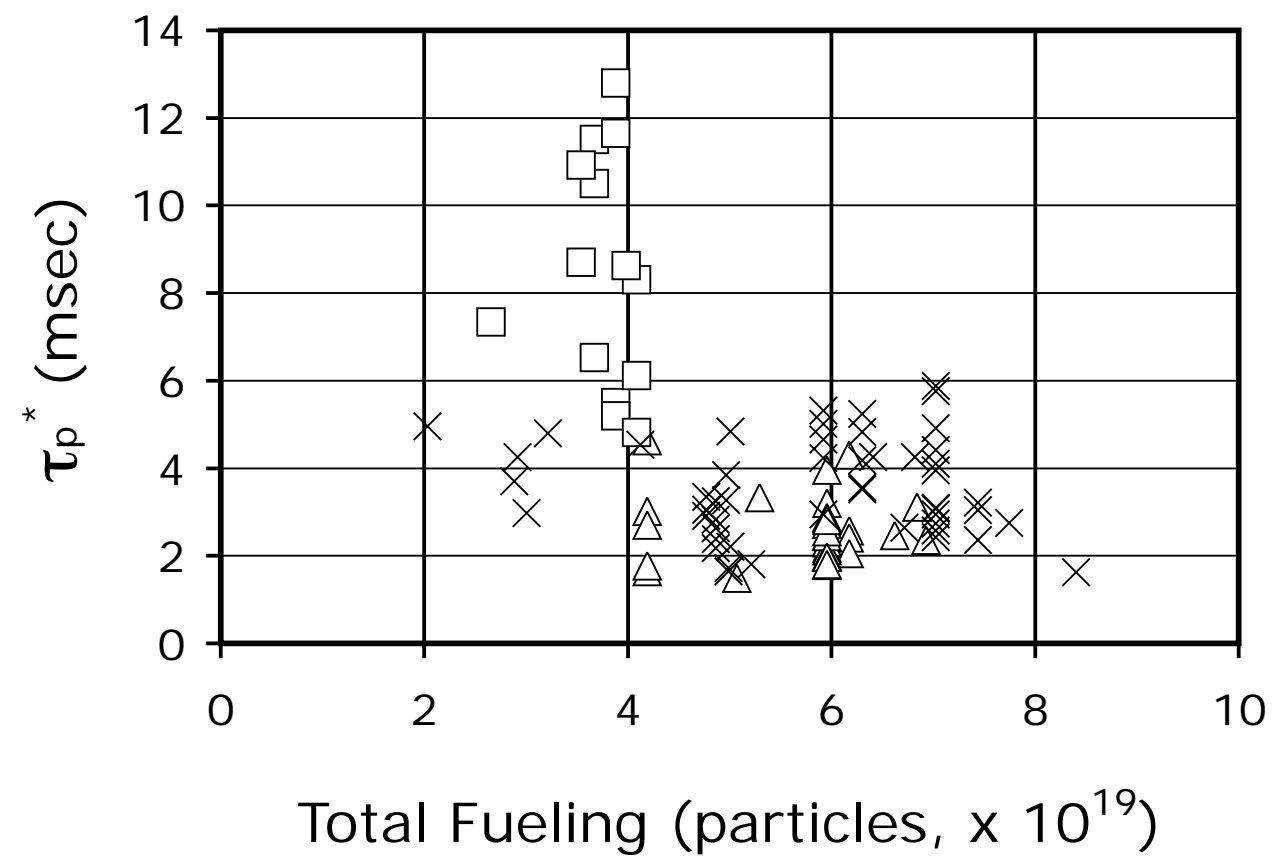

Figure 3 


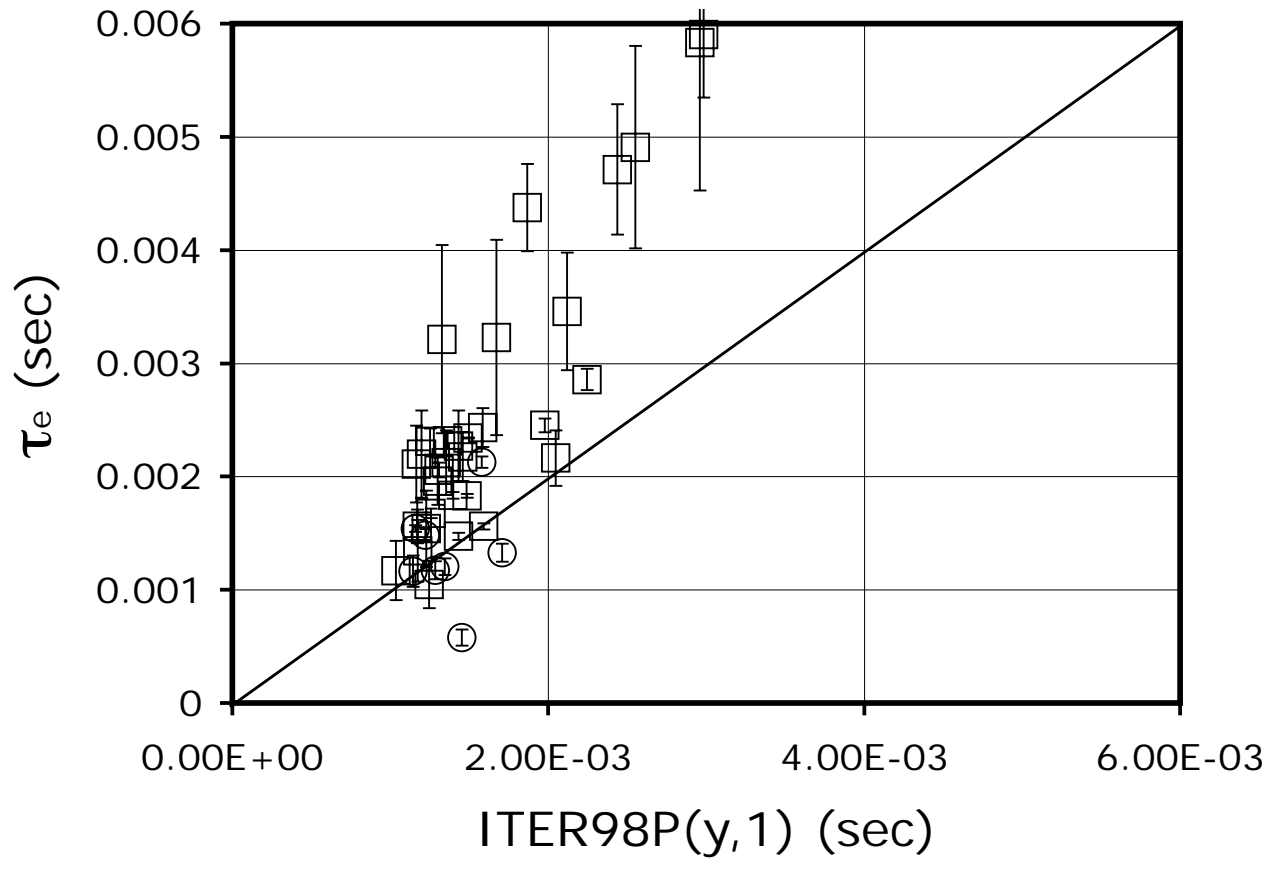

Figure 4 


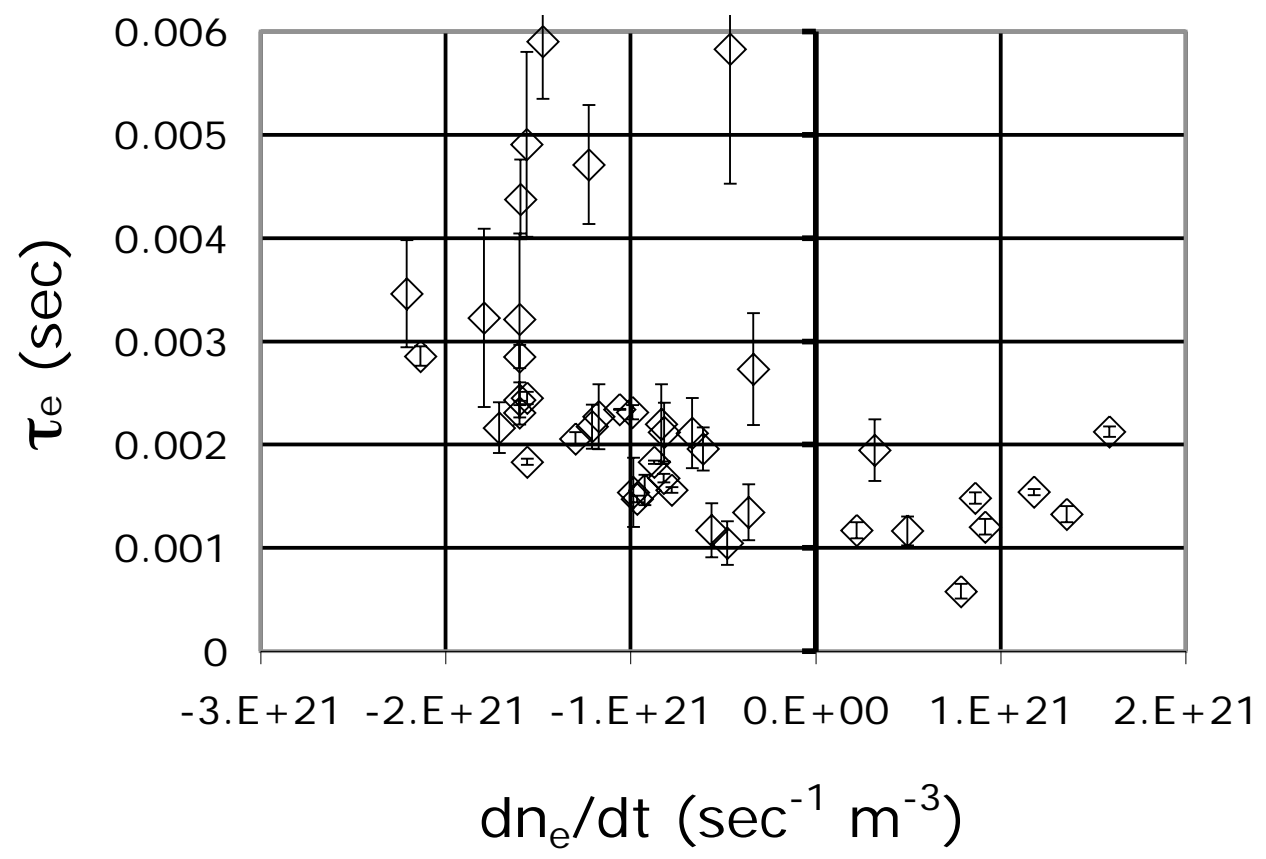

Figure 5 